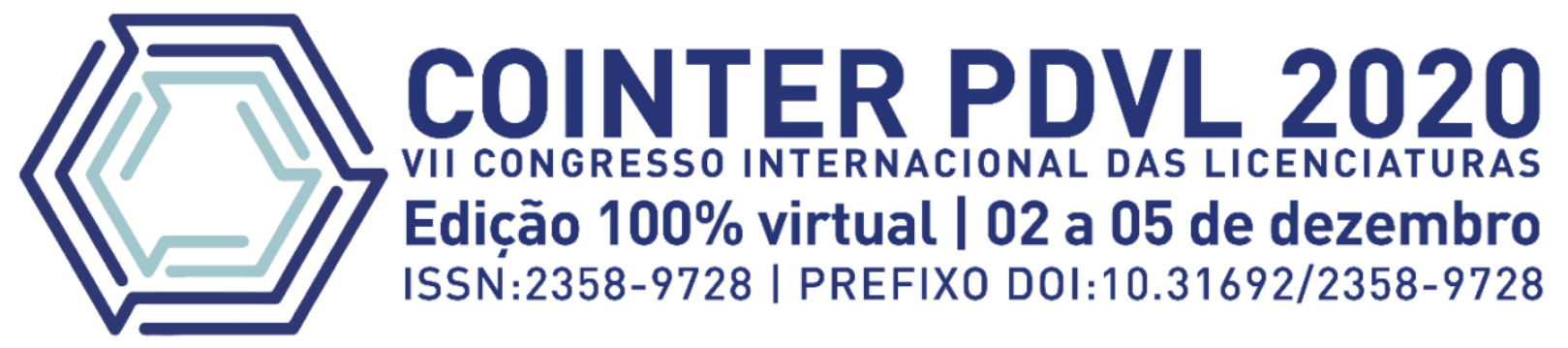

\title{
ANÁLISE DAS ATIVIDADES EXPERIMENTAIS PARA O ENSINO DE CIÊNCIAS NO SISTEMA DE EDUCAÇÃO À DISTÂNCIA
}

\section{ANÁLISIS DE ACTIVIDADES EXPERIMENTALES PARA LA ENSEÑANZA DE LAS CIENCIAS EN EL SISTEMA DE EDUCACIÓN A DISTANCIA}

\section{ANALYSIS OF EXPERIMENTAL ACTIVITIES FOR SCIENCE TEACHING IN THE DISTANCE EDUCATION SYSTEM}

\author{
Apresentação: Comunicação Oral \\ Isadora dos Santos Pereira'; Aretuza Bezerra Brito Ramos²
}

DOI: https://doi.org/10.31692/23589728.VIICOINTERPDVL.0401

\begin{abstract}
RESUMO
A educação pode ser considerada como um processo histórico e transitório, que sofre alterações de acordo com o contexto sócio econômico e as condições em que se realiza, sendo assim precisa da sua adequação para atender as necessidades dos alunos. Assim, as formas de lidar com as construções de conhecimento e seus desdobramentos exigem metodologias e ações diferenciadas, que são inéditas para algumas pessoas. É necessário que o professor atue no sentindo de não apenas apresentar, e sim desenvolver conceitos, juntamente com a teoria envolvida na experimentação, tornando-se um orientador crítico na aprendizagem. Nesse sentido, as atividades experimentais, podem ser consideradas como um recurso facilitador da aprendizagem, sendo uma ferramenta didática importante e capaz de estimular o interesse dos alunos, bem como uma maior autonomia. Nesse contexto, o presente trabalho teve como objetivo analisar como ocorrem as atividades experimentais para o ensino de Ciências no modelo de educação à distância. Salienta-se que o estudo realizado quando as atividades educacionais encontravam-se com o ensino remoto a, devido a pandemia causada pelo COVID19. O trabalho consistiu nas etapas de revisão bibliográfica, seguindo com a coleta de dados que se deu por meio de uma pesquisa direcionada aos professores, e a tabulação dos resultados. Com a pesquisa foi possível constatar que, há alguns empecilhos para a concretização das atividades experimentais para os professores questionados quando a sua realização ocorre no ensino à distância, pois não há recursos suficientes e nem estratégias voltadas para essas ferramentas didática, e apesar de considerarem a atividade experimental uma forma de ensino importante e capaz de despertar o interesse dos alunos, os professores ainda não estão preparados para usá-la diante desse modelo de ensino a distância.
\end{abstract}

Palavras-Chave: Experimentação, Educação, Aprendizagem .

\footnotetext{
${ }^{1}$ Licenciatura em Ciências Biológicas, FACHUSC, santosisadora011@ hotmail.com

${ }^{2}$ Mestre em Gestão e Políticas Ambientais, FACHUSC, aretuza.ramos@ fachusc.com
} 


\section{RESUMEN}

La educación puede ser considerada como un proceso histórico y transitorio, que cambia según el contexto socio-económico y las condiciones en las que se desarrolla, por lo que debe adaptarse a las necesidades de los estudiantes. Así, las formas de abordar las construcciones del conocimiento y su despliegue requieren de diferentes metodologías y acciones, inéditas para algunas personas. Es necesario que el docente actúe en el sentido no solo de presentar, sino de desarrollar conceptos, junto con la teoría involucrada en la experimentación, convirtiéndose en un asesor crítico en el aprendizaje. En este sentido, las actividades experimentales se pueden considerar como un recurso que facilita el aprendizaje, siendo una importante herramienta didáctica y capaz de estimular el interés de los estudiantes, así como una mayor autonomía. En este contexto, el presente estudio tuvo como objetivo analizar cómo las actividades experimentales para la enseñanza de las ciencias ocurren en el modelo de educación a distancia. Cabe destacar que el estudio realizado cuando las actividades educativas se encontraron con la educación a distancia debido a la pandemia provocada por COVID-19. El trabajo consistió en las etapas de revisión bibliográfica, seguida de la recolección de datos que se llevó a cabo a través de una investigación dirigida a docentes, y la tabulación de resultados. Con la investigación se pudo constatar que, existen algunos obstáculos para la realización de las actividades experimentales para los docentes cuestionados cuando su realización se da en la enseñanza a distancia, porque no existen suficientes recursos ni estrategias dirigidas a estas herramientas didácticas, y aunque consideran la La actividad experimental, una forma importante de enseñanza capaz de despertar el interés de los estudiantes, los docentes aún no están preparados para utilizarla de cara a este modelo de educación a distancia.

Palabras Clave: Experimentación, Educación, Aprendizaje.

\section{ABSTRACT}

Education can be considered as a historical and transitory process, which changes according to the socioeconomic context and the conditions in which it takes place, so it needs to be adapted to meet the needs of students. Thus, the ways of dealing with knowledge constructions and their unfolding require different methodologies and actions, which are unprecedented for some people. It is necessary for the teacher to act in the sense of not only presenting, but developing concepts, together with the theory involved in experimentation, becoming a critical advisor in learning. In this sense, experimental activities can be considered as a resource that facilitates learning, being an important didactic tool and capable of stimulating students' interest, as well as greater autonomy. In this context, the present study aimed to analyze how experimental activities for science teaching occur in the distance education model. It should be noted that the study carried out when educational activities met with remote education due to the pandemic caused by COVID-19. The work consisted of the stages of bibliographic review, followed by the collection of data that took place through a research directed at teachers, and the tabulation of results. With the research it was possible to verify that, there are some obstacles for the accomplishment of the experimental activities for the questioned teachers when its accomplishment occurs in the distance teaching, because there are not enough resources nor strategies directed to these didactic tools, and although they consider the experimental activity an important form of teaching capable of arousing the interest of students, teachers are not yet prepared to use it in the face of this distance learning model.

Keywords: Experimentation, Education, Learning

\section{INTRODUÇÃO}

A educação pode ser considerada como um processo histórico e transitório, que sofre alterações de acordo com o contexto sócio, econômico e as condições nas quais ocorre, dessa forma é necessário que se faça uma adequação nesse processo levando em consideração as necessidades dos alunos (BUENO; GOMES, 2011). Nesse cenário a Educação à Distância $(\mathrm{EaD})$ é parte natural do futuro da escola e da universidade. 
Entretanto, para se falar em Educação a Distância é necessário superar o simples ensino e a simples ilustração. Talvez fosse o caso distinguir os momentos, sem dicotomia. Salienta-se que essa é uma proposta para socializar informação, transmitindo-a de maneira mais hábil possível, mas, exige aprender a aprender, elaboração e consequente avaliação (DEMO, 1994).

Para Garcia (1995), a Educação à Distância é um sistema tecnológico de comunicação bidirecional, que substitui o contato pessoal professor/aluno, como meio preferencial de ensino, pela ação sistemática e conjunta de diversos recursos didáticos e pelo apoio de uma organização e tutoria, que possibilitam a aprendizagem independente e flexível dos alunos.

Preti (1996), afirma que a EaD deve ser compreendida como uma modalidade a qual se faz a educação pela democratização do conhecimento, onde esse conhecimento deve estar disponível a quem se dispuser a conhecê-lo, independentemente do lugar, do tempo, e de engessadas estruturas formais de ensino. É uma alternativa pedagógica que dispõe o educador e as instituições escolares.

No entanto, enquanto o processo de ensino vem sofrendo alterações, nas ultimas décadas o ensino de Ciências vem sendo norteado pela prática tradicional, ocasionando a discriminação por parte dos discentes. Diferentemente do que é preconizado pelos Parâmetros Curriculares Nacionais do Ensino Médio (PCNEM), quando ressalta que "os conteúdos de Biologia devem propiciar condições para que o educando compreenda a vida como manifestação de sistemas organizados e integrados" (BRASIL, 2006, p.20).

Silva (2013) afirma que apesar dos seus conteúdos fazerem parte do dia a dia da comunidade escolar, a ausência de contextualização no ensino dessa disciplina com os fatos que acontecem no cotidiano do estudante, impossibilita que o mesmo estabeleça relações entre a produção científica e o seu contexto, caracterizando dessa forma o motivo pelo qual muitos alunos não despertam interesse pela disciplina.

Com isso, o ensino de ciência, em sua fundamentação, requer uma relação constante entre a teoria e a prática, entre conhecimento científico e senso comum. No entanto, não deve ser encarada como uma prática pela prática, de forma utilitária, e sim uma prática transformadora, adaptada à realidade, com objetivos bem definidos, ou seja, a efetivação da práxis (KOLAVICZN, 1999).

Para Sacramento e Sonneville (2005), nunca é demais lembrar o papel que o planejamento dos conteúdos e do docente, criativo, inovador, provocador, que busque a quebra do paradigma da educação presencial, calcada na educação bancária, ou seja, de que o conhecimento é algo pronto e acabado a ser aprendido através da memorização e da reprodução de conceitos ditados pelo professor. 


\section{ATIVIDADE EXPERIMENTAL NO ENSINO REMOTO}

O ensino experimental tem o papel de ser um recurso auxiliar, capaz de assegurar uma transmissão eficaz do conhecimento científico. Ele iria promover a memorização dos enunciados teóricos, e reforçaria a convicção dos alunos quanto à plausibilidade daqueles conhecimentos que já haviam sido apresentados (BRAGA; LIMA; AGUIAR JUNIOR, 1999).

Nesse sentido, o objetivo deste estudo foi analisar como ocorrem as atividades experimentais para o ensino de Ciências no modelo de educação à distância.

\section{FUNDAMENTAÇÃO TEÓRICA}

As formas de lidar com as construções de conhecimento e seus desdobramentos exigem metodologias e ações diferenciadas, que são inéditas para algumas pessoas. Por isso, apesar de muitos docentes compreenderem a importância dos meios de comunicação e das múltiplas tecnologias na história social contemporânea, ainda é necessário potencializar determinadas mediações que acontecem com o uso de diferentes tecnologias no contexto educativo à distância (HACK, 2011).

Assim, na Educação à Distância (EaD), o docente possui um papel imprescindível na comunicação educativa que se estabelece no processo de ensino e aprendizagem, pois ele coopera com o aluno ao formular problemas, provocar interrogações ou incentivar a formação de equipes de estudo. $\mathrm{O}$ docente se torna memória viva de uma educação que valoriza e possibilita o diálogo entre culturas e gerações (MARTIN BARBERO, 1997).

Desta forma, é necessário que o professor atue no sentindo de não apenas apresentar, e sim desenvolver conceitos, juntamente com a teoria envolvida na experimentação, tornando-se um orientador crítico na aprendizagem, compreendendo assim que a sala de aula é palco de uma matriz de variáveis que diretamente influenciam as decisões do ensino, deixando de lado o autoritarismo no seu modo de ensino, possibilitando que os alunos criem seu próprio conceito sobre o ensino de Ciências (LABURÚ; ARRUDA; NARDI, 2003).

Marandino (2003), afirma que o ensino de ciências é essencial, pois ajuda o aluno a desenvolver seu raciocínio lógico e racional, além da aprendizagem. Vale salientar que, as atividades experimentais têm o dever de evitar que a relação da teoria com a prática seja transformada em uma dicotomia.

Santos (2005) enfatiza que o ensino de Ciências através da experimentação se torna quase uma necessidade no âmbito das ciências naturais. Acontece que pode perder o sentido da construção científica se não relacionar experimentação, construção de teorias e realidade socioeconômica e se não valorizar a relação entre teoria e experimentação, pois ela é o próprio cerno do processo científico. 
Existem diversas atividades no ensino de Ciências que possibilita a interação dos alunos com o conteúdo, nessas atividades há aproximação com os materiais, e com os recursos que são capazes de promover a comunicação dos alunos entre sí, ou entre aluno-professor, haja vista que o docente tem a função de ajudar o estudante a traçar caminhos que favoreçam a sua aprendizagem de modo significativa e que permita ao educando ter vontade de aprender, e de solucionar questões que lhes são apresentadas (RINALDI, 2011).

O professor deve conviver com os estudantes, observando suas ações, dialogando com eles, perguntando, sendo interrogado, e realizar também diversas experiências do cotidiano do ensinar e do aprender. Esse procedimento auxiliará na aprendizagem e desenvolvimento intelectual e pessoal. Cabe ainda, trabalhar com os estudantes os aspectos afetivos dessa relação (RINALDI 2011, p. 18)

O Governo do Estado do Paraná (2007, p. 76) defende a ideia de que essas atividades não dependem do laboratório escolar para a sua realização, podendo ser desenvolvidas em outros espaços pedagógicos, como a sala de aula, e utilizar materiais alternativos. Contudo, é de suma importância que essas práticas proporcionem discussões, interpretações e coincidam com os conteúdos trabalhados. Não devem ser apenas momentos de comprovação de leis e teoria ou somente ilustrações das aulas teóricas.

Para além de conteúdos específicos, uma atividade de campo permite também estreitar as relações de estima entre o professor e alunos, que possa proporcionar momentos de interações e descobertas entre os alunos e o meio ambiente, tentando enxergar e solucionar problemas ao seu redor e favorecendo um companheirismo resultante da experiência em comum e da convivência agradável entre os sujeitos envolvidos que perdura na volta ao ambiente escolar (VIVIERO; DINIZ, 2009 p. 4).

\section{METODOLOGIA}

Este estudo trata-se de uma pesquisa com abordagem qualitativa, enfatizando o processo de ensino-aprendizagem, que teve como público os professores de Ciências, que atuam na rede pública e privada do município de Salgueiro, localizado no Sertão Central Pernambucano (figura 1). Vale ressaltar que, as escolas, no momento da realização deste estudo (agosto a setembro de 2020) passavam por um processo de ensino a distância, decorrente da pandemia causada pelo COVID-19, a qual afetou vários setores, dentre eles a Educação.

Assim, o estudo consistiu em duas etapas, sendo realizada inicialmente uma revisão bibliográfica afim de um maior embasamento teórico, seguindo com a coleta e tabulação de dos dados. 
Figura 01:Área de estudo, destacando o município de Salgueiro- Pernambuco.

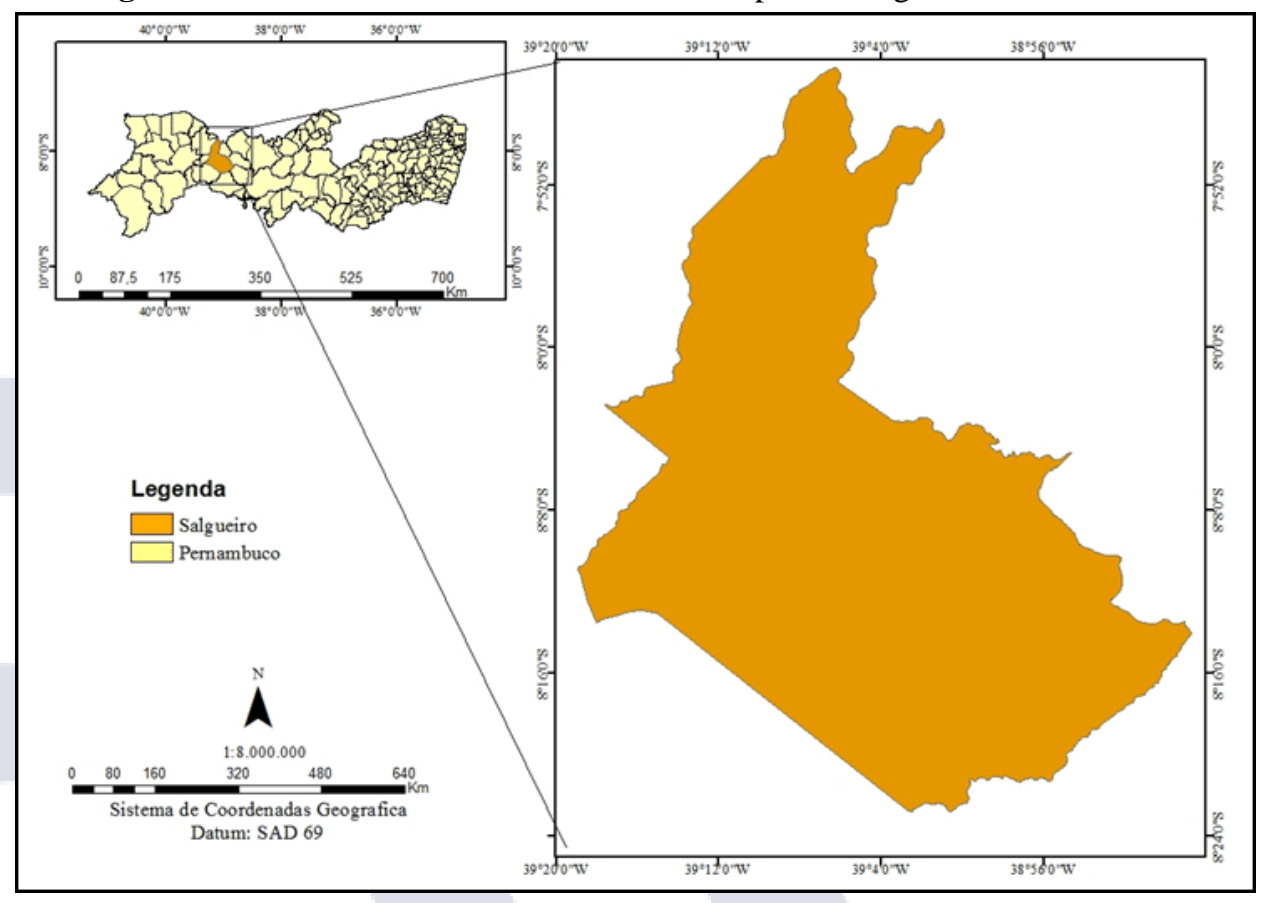

Fonte: IBGE (2020).

Para a coleta de dados utilizou-se de questionários digitais semiestruturados, com por sete perguntas objetivas e subjetivas. A aplicação do questionário foi feita por mídias sociais, no qual foi disponibilizado um link direcionado a cada professor para que eles respondessem e reenviassem contendo todas as suas respostas.

\section{RESULTADOS E DISCUSSÃO}

Os professores de Ciências entrevistados nesse estudo reconhecem à relevância das aulas experimentais, uma vez que todos responderam que as aulas experimentais são ferramentas didáticas de suma importância.

Ressaltando a importância das atividades experimentais, Paraná (2008, p. 23) destaca que "a experimentação [...] pode favorecer a quebra de obstáculos na aprendizagem de conceitos científicos, além de propiciar interpretações, discussões e confronto de ideias entre estudantes, inclusive de incentivar a investigação".

Krasilchik (2005, p. 86) relata que "as aulas experimentais têm um lugar insubstituível no ensino da Biologia, pois desempenham funções únicas: permitem que os alunos tenham contato direto com os fenômenos, manipulando os materiais, equipamentos e observando organismos".

Segundo Morais (2015), quando a atividade experimental é bem planejada e contextualizada pode auxiliar o discente na compreensão dos princípios científicos, bem como 
articular uma ligação entre a teoria e prática no processo de ensino aprendizagem. $\mathrm{O}$ autor afirma ainda que "[...] o docente deve ter clareza na definição e diferenciação dos termos atividades práticas e atividades experimentais, até porque atividades práticas podem ser entendidas de muitas formas e como elas podem gerar confusão ao docente".

No entanto, no presente estudo, ao selecionar os pontos positivos de uma aula experimental, 66,7\% dos professores alegaram haver uma maior interação do aluno com o professor, porém os demais reconhecem a maior motivação para uma autonomia por parte dos alunos, fato esse destacado por Soares et al. (2013, p. 03) quando afirmam que atividades experimentais "proporcionam a participação ativa do aluno na etapa de construção do conhecimento, o que pode atuar como agente motivador para os alunos".

Seré (2002) Enfariza que, o “fazer" não é o bastante para “aprender”. É imprescindível fazer e ter a consciência do que se faz para aprender a todos os procedimentos e saber usá-los. Dessa forma, para essa conscientização é necessário uma maior autonomia por parte dos alunos durante as aulas experimentais.

Para Knuppe (2006), a motivação deverá estar relacionada aos objetivos e metas destacados pela atividade, desse modo, um bom professor deve possuir metas de ensino, e isso tornará o aluno motivado a querer aprender. Essas metas são desencadeadoras da conduta motivada, portanto, sem desejos e metas não há motivação. Para que haja aprendizagem, é necessário haver motivação.

Malacarne e Strieder (2009) defendem que a experimentação tem o poder de motivar os alunos, estimulando a investigação sobre os temas propostos, incentivando a sua participação na aula e contribuindo para a possibilidade efetiva de aprendizagem.

Porém, de acordo com HODSON (1994), a utilização de atividades experimentais para motivar os alunos é primeiramente um equívoco, não são todos os alunos que sentem-se motivados, inclusive alguns alunos possuem aversão a esses tipos de atividades. Outro ponto, é que as expectativas em relação a experimentação diminuem de acordo com os alunos começam a realizar esse tipo de atividade.

Ressalta-se que, os professores questionados neste estudo afirmaram que um dos pontos negativos para a realização das aulas experimentais é a falta de um espaço apropriado, os demais afirmaram que seria a falta de material adequado, acrescentaram que a falta de interesse dos alunos também conta como aspecto negativo a ser considerado (figura 2).

Contudo, o que se observa é que essas atividades ou não acontecem por falta de espeços apropriados ou por falta de materias específicos, mas talvez por falta de preparo dos professores que não tiveram em sua formação aulas direcionadas para essa finalidade. Desta forma, quando 


\section{ATIVIDADE EXPERIMENTAL NO ENSINO REMOTO}

as atividades acontecem visam apenas relacionar teoria e prática não provocando assim uma aprendizagem significativa (PARANÁ, 2014).

Enfim, sabe-se que estudos mostram que as aulas de ciências onde o professor usa apenas recursos didáticos limitados como livro didático e quadro negro não promovem uma aprendizagem significativa. "A tarefa docente consiste em trabalhar o conteúdo científico e contrastá-lo com o cotidiano, a fim de que os alunos, ao executarem inicialmente a mesma ação do professor, através das operações mentais de analisar, comparar, explicar, generalizar, etc., apropriem-se dos conceitos científicos e neles incorporem os anteriores, transformando-os também em científicos constituindo uma nova síntese mais elaborada" (GASPARIN, 2002 p.58).

Figura 02: Pontos negativos na realização de uma aula experimental conforme os professores de Ciências do município de Salgueiro-PE.

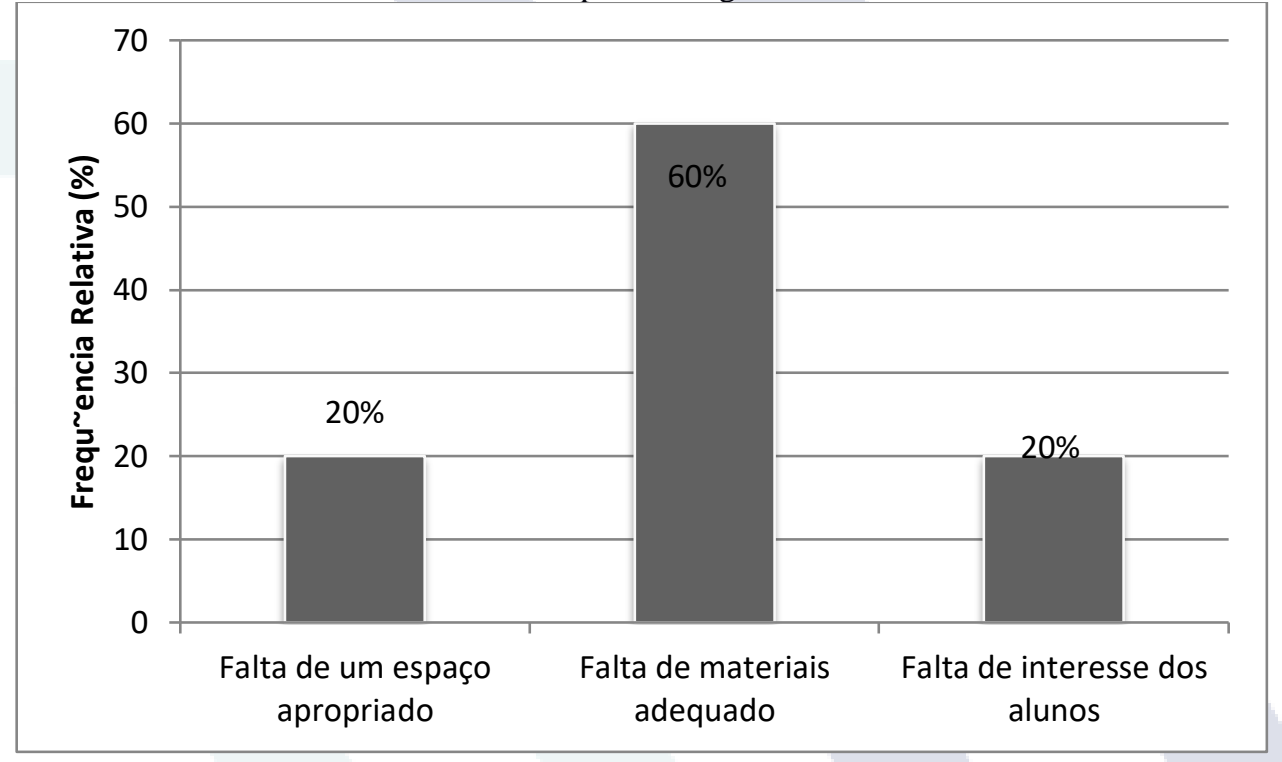

Fonte: Própria (2020)

Quando questionados sobre o tempo de duração da aula ser um empecílio para realização das atividades experimentais, os docentes informaram que esse não é um empecilho para a realização de uma aula experimental. Os fatos observados corroboram com Salvadego; Laburú e Barros (2009) quando afirmam que os experimentos podem ser realizados em laboratório com equipamentos tecnológicos, mas também na sala de aula com materiais caseiros carregam a mesma importância. Nesse sentido, os experimentos poderiam ser conduzidos pelo professor, mesmo a distância, e os alunos os desenvolveriam utilizando os recursos disponíveis em suas residências tendo a supervisão de um responsável.

Entretanto, KRASILCHIK (2008) afirma que as aulas de laboratório são insubstituíveis 
para a disciplina de Ciências, uma vez que desempenham papéis importantes, onde possibilita o contato direto dos alunos com os fenômenos, na manipulação ou observação dos materiais e equipamentos.

Para Souza et al. (2016) é necessário iniciar um espaço para perguntas, estimular a curiosidade, são nesses momentos que o aluno demonstra interesse e começa a dialogar. Esse ato aproxima professor e aluno, estabelece um diálogo entre a turma e auxilia na aprendizagem.

Laburú ( et al, 2006) Afirma que é necessário reconhecer que há uma dependência entre as estratégias eficientes e a capacidade que elas possuem de incentivar a motivação da maioria dos alunos.

Para os entrevistados, a aula experimental é uma ferramenta que possibilita o aluno a relacionar a teoria com a prática. Porém, Silva e Zanon (2000) afirmam que há muitos professores que acreditam na comprovação da teoria através da prática, e por isso pensam que essa seja a finalidade da experimentação no ensino de Ciências. O correto seria considerar o inverso, que por meio da prática realizada pelos alunos seja possível chegar por descoberta, a uma determinada teoria que já havia sido estudada, e até mesmo buscar abranger um determinado conteúdo antes da teoria.

Com relação a prática de atividade experimental no período de pandemia, $60 \%$ dos entrevistados afirmaram que não realizarem. Entretanto, Delizoicov (1992, p. 07 ) defende que, a experimentação é uma ferramenta didática eficaz no processo de ensino-aprendizagem, quando são orientadas de uma maneira que dê espaço a discussões e interpretações dos resultados obtidos, assegurando situações de investigação e estimular o interesse do aluno para a apreensão do conhecimento. Desta forma, considera-se viável a utilização dessa prática, mesmo sendo realizada a distância.

Em relação as maiores dificuldades para a não realização de uma aula experimental à distância vista pelos profissionais questionados por este estudo foi a falta de material por parte dos alunos $(85,7 \%)$, e o fato considerarem a falta de interesse dos alunos (14,3\%). Segundo Chalmers (1999), é necessário perceber a importância do desenvolvimento da experimentação, não somente pelo estímulo em despertar o interesse dos alunos perante conteúdos específicos em Ciências, como também para ter consciência do seu constante avanço. Para que se torne possível a obtenção de dados do progresso do estudante, o recurso da aula experimental tornase necessário.

Para HESS (1997), é papel do professor encontrar alternativas, coo por exemplo, a realização de experimentos com materiais encontrados em casa, pois o grande objetivo da experimentação é possibilitar que o aluno retrate aquilo que tem sentido para ele, a partir de sua 


\section{ATIVIDADE EXPERIMENTAL NO ENSINO REMOTO}

observação.

Ao pedir para descreverem as aulas experimentais no sistema de ensino remoto, os professores que haviam realizado as aulas experimentais, citaram que a aula girou em torno da preparação do material, da realização de um vídeo feito por cada aluno e a divulgação na plataforma de ensino. Por outro lado, Bizzo (2002, p.75) defende que, o experimento por si só não é a confirmação da aprendizagem, pois não é suficiente para modificar a maneira de pensar dos alunos, o que demanda acompanhamento contínuo do professor, que necessita explorar quais são as explicações apontadas pelos alunos para os resultados encontrados, e quem sabe se necessário, propor uma nova situação e investigação 


\section{CONCLUSÕES}

Esse estudo constatou que, no processo de ensino remoto há pouca utilização de aulas experimentais. Mas, é necessária uma reflexão sobre a importância das atividades experimentais no ensino de ciências, uma vez que, ao abordar somente aulas teóricas ou utilizando-se apenas de métodos tradicionais, a disciplina de ciências fica sem atrativo para os alunos, e os mesmos se mostrarão desinteressados e não conseguirão relacionar a teoria com a prática.

Portanto, é notável que os todos os professores entrevistados, consideram a experimentação importante, tanto para eles quanto para os alunos. A experimentação por si só não garante o aprendizado, mas se os alunos e professores estiverem dispostos a "criar" um ambiente propício para a realização desses experimentos, certamente haverá melhoria no processo de ensino-aprendizagem.

\section{REFERÊNCIAS}

BIZZO, Nélio Marcos V. Ciências: fácil ou difícil. São Paulo: Ática, 2002. P. 74-75

BRAGA, S.A. de, M; LIMA, M. E. C. de, C.; AGUIAR-JUNIOR, A. Aprender Ciências: um mundo de materiais. Belo Horizonte: UFMG, 1999.

BRASIL, Ministério da Educação e da Cultura. Secretaria de Educação Básica. Orientações Curriculares para o Ensino Médio, Ciências da Natureza, Matemática e Suas Tecnologias. Brasília, v.2, 135 p. 2006.

BUENO, J.L.P.; GOMES, M.A. de O. Uma análise histórico-crítica na formação de professores com tecnologias de informação e comunicação. Revista Cocar Belém, vol. 5, n. 53, 2011.

CHALMERS, A. F. O que é Ciência afinal? São Paulo: Brasiliense, 1999.

DELIZOICOV, D.;ANGOTTI, J. A. Metodologia do Ensino de Ciências. São Paulo: Cortez, 1992.

DEMO, P. Pesquisa e construção de conhecimento: metodologia científica no caminho de Habermas. Rio de Janeiro. Tempo Brasileiro, 1994.

GARCÍA ARETIO, L. (1995): Educación a distancia hoy. Madrid, UNED, (Collección Educación Permanentel.

Governo do Estado Paraná. Secretaria Estadual de Educação. Diretrizes Curriculares de Ciências para o Ensino Fundamental. Cutitiba: Secretaria do Estado da Educação, 2007.

HACK, J. R Introdução à educação a distância -Florianópolis: LLV/CCE/UFSC, 2011. 126 p.:iL. 
HESS, S. Experimentos de química com materiais domésticos: ensino médio. São Paulo. Moderna, 1997.

HODSON, D. Em direção a uma abordagem mais crítica para o trabalho de laboratório. Ensino de Ciências, V.12, n 3, p. 299-313, 1994.

KOLAVICZN, R. A. O professor de Ciênsias e de Biologia frente a parasitoses comuns em escolares. Mestrado em Educação. UEPG, 1999 (Dissertação).

KNUPPE, L. Motivação e Desmotivação:desafios para as professoras do ensino fundamental. Editora UFPE, Educar, Curitiba, n.27, p. 277-290, 2006.

KRASILCHIK, M. O professor e o currículo das Ciências. São Paulo: EPU, 1987, p.80.

Paulo, 2016.

. Práticas de ensino de biologia. $4^{\mathrm{a}}$ ed. São Paulo: Editora da Universidade de São

LABURÚ, C. E.; ARRUDA,S. M.; NARDI, R. Fundamentos para um experimento cativante. Caderno Brasileiro de Ensino de Física, v. 23, n. 3: p.284- 404, dez. 2006.

LABURÚ, C. E; ARRUDA, S. M; NARDI, R. Pluralismo metodológico no ensino de ciências. Ciência \& Educação (Bauru). Programa de Pós-Graduação em Educação para a Ciência, Universidade Estadual Paulista (UNESP), Faculdade de Ciências, campus de Bauru., v. 9, n. 2, p. 247-260, 2003. Disponível em: 〈http://hdl.handle.net/11449/26453>. Acesso em 04 de maio de 2019.

MALACARNE, V; STRIEDER, D. M. O Desvelar da Ciência nos anos iniciais do Ensino Fundamental: Um olhar pelo viés da experimentação. Vivências. V.5, N. 7: p.75-8, mai.2009.

MARANDINO, M. A prática de Ensino nas Licenciaturas e a Pesquisa em Ensino de Ciências: Cad.Bras.Ens.Fís., v.20, n.2: p.168-193, ago.2003.

MARTIN BARBERO, J. Dos meios às mediações: comunicação, cultura e hegemonia. Rio de Janeiro: EdUFRJ, 1997.

MORAIS, V. C. da S. Atividades experimentais: implicações no ensino de Biologia. Dissertação apresentada ao programa de pós-graduação em ensono de ciências e matemática profissional da Universidade Federal de Uberlândia - UFU como requisito para obtenção de titulo de mestre em ensino de ciências e matemática. 2015. 20-144p.

PARANÁ. Secretaria do Estado da Educação do Paraná. Superintendência da Educação. Diretrizes Curriculares de Ciências para o Ensino Fundamental. Paraná, 2008.

PRETI, O. Educação à distância: uma prática mediadora e mediatizada, in. Educação á distância: inícios e indícios de um percurso. Cuiabá, UFMT, 1996.

RINALDI, C.; SANTOS, L. M. P. L.dos. Psicologia da aprendizagem e Educação Ética. Coleção Curso de Licenciatura em Ciências Naturais e Matemática, 2011, Cuiabá, Print Editora. 
SACRAMENTO, M. C.; A. F; SONNEVILLE, J. J. Docência online: Tecendo possibilidades para a prática educativa e para a pesquisa. Salvador: Mimeo, 2015.

SALVADEGO, W. N. C; LABURÚ, C.E; BARROS, M. A. Uso de atividades experimentais pelo professor das Ciências Naturais no ensino médio: relação com o saber profissional. Artigo apresentado no $1^{\circ}$ Congresso Paranaense de Educação em Química-CPEQUI, Agosto de 2009. 12p.

SANTOS, C.S. Ensino de Ciências: abordagem histórico- crítica. Campinas: Armazém do Ipê, 2005.

SERÉ, M. G. Ensino de laboratório: O que podemos aprender em termos de conhecimento prático e atitudes em relação a Ciência? Ensino de Ciências. v. 20, n.3, p357-368, 2002.

SILVA, M. L. da. A IMPORTÂNCIA DO ENSINO CONTEXTUALIZADO NA BIOLOGIA. Monografia apresentada como requisito parcial para obtenção do título de Licenciado em Biologia no Programa Especial de Formações de Docentes da Faculdade Integrada da Grande Fortaleza - FGF. ITAPAJÉ-CE. 2013. 10-37p.

SOARES, K. C. M et al. Experimentos de ciências nos anos iniciais do ensino fundamental: uma ferramenta para a motivação em sala de aula. Atas do In. ENCONTRO NACIONAL DE PESQUISA EM EDUCAÇÃO EM CIÊNCIAS, 9. São Paulo. UFRJ, 2013. Disponível em: http://www.nutes.ufrj.br/abrapec/ixenpec/. Acesso em :20 nov. 2015.

SOUZA, M. M. L; SOUZA, P. S. S; RAMOS, M. G. O interesse dos alunos em aprender ciências e matemática na escola. Revista de Extensão. Santa Maria v.3- n Ed. Especial. Encontro sobre Investigação na Escola. 2016, p. 1015-1021. Revista do Centro de Ciências Naturais e Exatas- UFSM ISSN on-line: 21794588

VIVEIRO, A. A.; DINIZ, R. E. S. Atividades de campo no ensino das ciências e na educação ambiental: refletindo sobre as potencialidades desta estratégia na prática escolar. CIÊNCIA NA TELA - Volume 2, Número 1 -2009. Disponivel em: $<$ https://www.researchgate.net/profile/Renato_Diniz2/publication/267235410_Atividades_de ades_desta_estrategia_na_pratica_escolar/links/54e4c02b0cf29865c334fb46.pdf> Acesso em 04 de maio de 2019. 